\title{
The Analysis and Probabilistic Health Risk Assessment of Polycyclic Aromatic Hydrocarbons in Cereal Products: with the Chemometric Approch
}

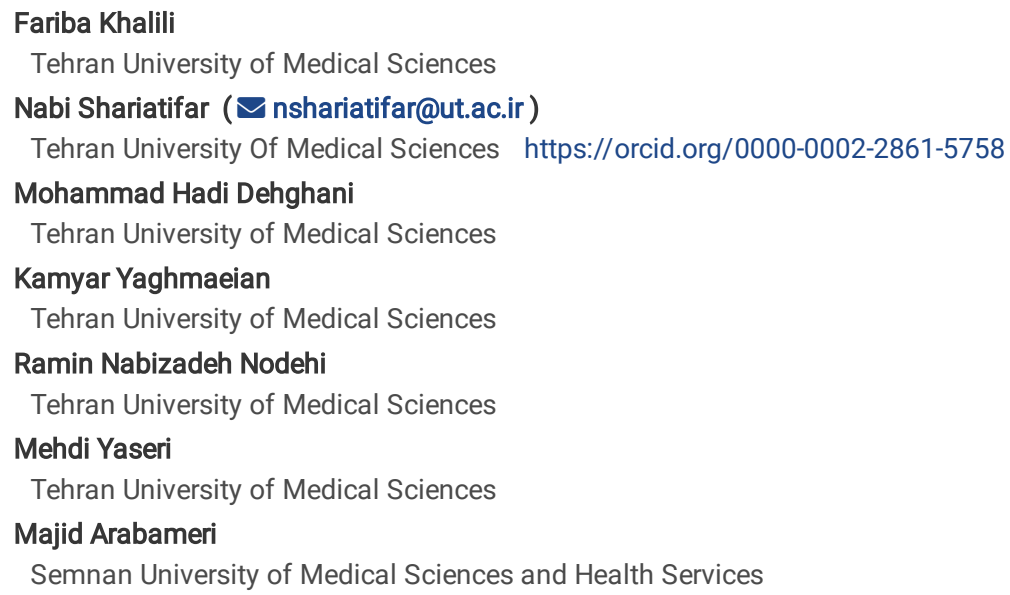

Keywords: Polycyclic aromatic hydrocarbons, Health risk assessment, Principal component analysis, Cereal products.

Posted Date: September 13th, 2021

DOI: https://doi.org/10.21203/rs.3.rs-697317/v1

License: (c) (i) This work is licensed under a Creative Commons Attribution 4.0 International License. Read Full License 


\section{Abstract}

The analysis and probabilistic health risk assessment of Polycyclic Aromatic Hydrocarbons (PAHs) in cereal products were done by using magnetic solidphase extraction (MSPE) method and gas chromatography/mass spectrometric (GC/MS). The level of sum sixteen PAHs in cereal products ranged from 98.2 (in Barbari bread) to $248.3 \mu \mathrm{g} / \mathrm{kg}$ (in rice cooked). Further, the correlation between the type and amount of 16 PAHs with cereal products samples evaluated with multivariate principal component analysis and heat map visualization. Estimation of incremental lifetime cancer risk in cereals ranged from $7.80 \mathrm{E}-6$ to 2.35E-7. In conclusion, the PAHs content in the tested products were in low health risk ranges $(1 \times 10-6<\mathrm{ILCR}<1 \times 10-4)$, and all of the cereal products sold in Tehran are considered safe for consumers. Therefore, cereal products should be regularly evaluated and monitored by regulatory agencies to reduce contaminants in these high-consumption products.

\section{Introduction}

Concerns over about the presence of PAHs, in foodstuffs as harmful to human health started during the 1960s and 1970s (Samiee et al. 2020b). Organic carbon compounds, such as PAHs, are obtained from sources such as vehicles, fossil fuel combustion, wood combustion, plant decomposition, and photochemical reactions. About $150 \mathrm{PAH}$ compounds have been identified so far, 16 of which have been reported by the Environmental Protection Agency (USEPA( in foodstuffs (Lee et al. 2019). These sixteen PAHs include naphthalene (NaP), acenaphthylene (AcPY), acenaphthene (AcP), fluorene (Flu), phenanthrene (Phe), anthracene (Ant), fluoranthene (FI), pyrene (Pyr), benz(a)anthracene (BaA), chrysene (Chr), benzo(b)uoranthene (BbFL), benzo(k)uoranthene (BkFL), benzo(a)pyrene (BaP), indeno(1,2,3-c,d) pyrene (InP), dibenz(a,h)anthracene (DBA) and benzo(g,h,i)perylene (BghiP). Among them, three PAHs (BaP, BaA and DahA) classified as probably carcinogenic to humans (group 2A) by the International Agency for Research on Cancer (IARC).(Mocek \&Ciemniak 2016). The European Commission (EC) has set a maximum BaP level for processed cereals of $1.0 \mu \mathrm{g} / \mathrm{kg}$ (Ma et al. 2019)

The important routes of contact to PAHs compounds are ingestion, inhalation and contact of dermal, and a serious concern exists about the contamination of PAHs in foodstuffs (Purcaro et al. 2013). Food can be contaminated with PAHs in the variety routes, including during production, packaging, cooking, and from environmental sources (water, soil, and air) (Lee et al. 2019). Therefore PAH compounds have been found as contaminants in some foods, including breads, cereals, smoked foods, seafood, milk and dairy products, meat and meat products, vegetables, fruits, fats and oils (Moazzen et al. 2013, Xia et al. 2010). Although they may have less contaminated cereal products, their frequent consumption causes high levels of PAH to be stored in humans(Rascon et al. 2018). For many people around the world, bread is the important source of energy and protein and is considered a staple food. Bread contains minerals, vitamins, proteins and carbohydrates and is therefore an essential nutrient in human nutrition, especially in developing countries.

The breads that are consumed in the food basket of the Iranian household include such as Lavash, Taftoon, Sangak, Barbari and industrial breads. According to studies on bread consumption in Iranian families, the highest percentage of consumption related to Lavash bread was $39.1 \%$ and then Sangak and Barbari bread was $13.8 \%$ and $10.7 \%$, respectively(Jahed Khaniki et al. 2021).

Pasta is another cereal that is a hard wheat product that is not made from unleavened dough and comes in a variety of forms and is usually boiled for consumption(Ihedioha et al. 2019). The pasta that are commonly consumed in Iran include noodles, macaroni and spaghetti. They are quite popular because of the minimum time needed to prepare them, ease of preparation and low cost.

Contamination of cereal-based foods with PAHs can be attributed to contamination caused by cereals during the production process, the flour production process and especially to the cooking process.

For accurate and precise measurements, chromatographic techniques using gas chromatography (GC) or liquid chromatography (LC) have been advanced and assessed extensively. In comparison to LC, however, GC is preferred, as it typically affords greater selectivity, resolution and sensitivity for separation, identification and quantification of PAHs(Lee et al. 2018). In addition, it is essential to use an effective method to extract and clean up food (Sadowska-Rociek et al. 2014). During the recent years, various methods of sample pretreatment have been applied for PAHs separation and pre-concentration in food samples including stir-bar sportive extraction (SBSE), solid-phase extraction (SPE), and solid-phase micro-extraction (SPME). Based on magnetic nanoparticles, MSPE has been recently established as a promising method of sample preparation. In the MSPE method, magnetic adsorbents are regularly and directly dispersed into the sample solution (Kiani et al. 2018, Kouhpayeh et al. 2017, Moazzen et al. 2019). Moreover, magnetic adsorbents are recyclable. Therefore, MSPE offers some obvious benefits such as easiness and timesaving features, labor and cost (Shi et al. 2016). Finally, the purified extract is analyzed by liquid or gas chromatography with diverse kinds of detectors (Kiani et al. 2018, Moazzen et al. 2013, Sadowska-Rociek et al. 2014).

In most studies, BaP often used as a marker for PAHs in food (12). The carcinogenic characteristic of PAHs is a great deal of concern. The BaP toxic equivalency factors (TEFs) are accepted to estimation the carcinogenic potency of PAHs (Qiao et al. 2006).

Considering the comparatively high ratio of cereal products in the food basket of Iran it is important to test the concentration of PAHs in cereal products in Iran. So far low comprehensive study has been done on cereal products. Therefore, the aims of the current study are as follows: (1) to develop a simple, fast and reliable technique for the analysis of PAHs in cereal products to eliminate the need of multi-phases column elution procedure using MSPE adsorbent and GC-MS, and (2) to assess the potential human health risk made by PAHs intake by the cancer potency of BaP as a member of reference.

\section{Materials And Methods}

\subsection{Samples}


Sixty four cereal product samples were randomly purchased (in triplicate) from different supermarkets located in Tehran, Iran. Types of breads (Sangak, Barbari, Baguette, Taftoun and Lavash) and other cereal products (macaroni, lasagna and rice cooked (Chelo)) were covered. All samples were crushed and ground to produce a homogeneous particle size and stored in glass bottles with lids in the refrigerator-freezer at $-20^{\circ} \mathrm{C}$ for analysis. All samples were analysed in triplicate.

\subsection{Standards and Reagents}

Polycyclic aromatic hydrocarbons (PAHs) mix standards containing sixteen PAHs were purchased from Supelco Company (Bellefonte, PA, USA). These mixtures were naphthalene (NAP), benzo[k]fluoranthene (BkF), fluorine (FLO), phenanthrene (PHE), benzo[a]pyrene (BaP), acenaphthylene (ACY), Acenaphthene (ACE), fluoranthene (FLA), anthracene (ANT), benz[a]anthracene (BaA), Pyrene (PYR), chrysene (CHR), benzo[b] fluoranthene (BbF), dibenzo[a, $h]$ anthracene (DahA), benzo[g,h,i] perylene (BghiP) and indeno[1,2,3-cd] Pyrene (IcdP). The solution of stock standard was mixed with dichloromethanemethanol $(50: 50, \mathrm{v} / \mathrm{v})$ every week ( $2 \mu \mathrm{g}$ per $\mathrm{mL}$ for each mentioned PAHs) that was applied to measure the extraction function with various situations. Afterward, solutions of stock and working were kept at $4^{\circ} \mathrm{C}$. As the internal standard (I.S), biphenyl was applied at a concentration of $0.1 \mu \mathrm{g} / \mathrm{mL}$ in methanol.

\subsection{Sample preparation and analysis}

The samples were ready based on a 3 part process including:

a. Sample clean-up

Five grams of prepared bread and other cereal products were weighed and $1 \mathrm{~mL}$ of the I.S was added, followed by adding $7.5 \mathrm{milliliters} \mathrm{methanol/acetonitrile}$ (30\%:v/v) and $7.5 \mathrm{~mL}$ potassium hydroxide $(1 \mathrm{M})$. Then. The mixture were homogenized and sonicated in an ultrasonic bath for 6 minutes at $40^{\circ} \mathrm{C}$. Afterward, the ready sample was centrifuged for ten minutes at $8944 \times \mathrm{g}$, and then the fat was removed by the freezing-lipid filtration method (Ahmadkhaniha et al. 2009). Finally, by adding hydrochloric acid) $1 \mathrm{M}$ ), the $\mathrm{pH}$ was adjusted to 6.5 .

\section{b. Analyte adsorption}

After the previous procedure, the aqueous phase was transferred to another vessel. Afterward, ten milligrams of adsorbent (multi-walled carbon nanotube/CoFe2O4 (MWCNT/ CoFe204)) composite were ready (Moazzen et al. 2013) and $\mathrm{NaCl}(500 \mathrm{mg})$ was added into the mixture. Then, the prepared samples was mixed (vigorously) for 6 minutes with a mechanical mixer. Finally, to collect the magnetic adsorbent (containing PAHs contaminant) to one side of the vial, the exterior magnet was used (Samiee et al. 2020a).

c. Analyte desorption from the magnetic adsorbent

Five milliliters of dichloromethane was added and vortexed (to desorb PAHs contaminants from the adsorbent), and then the supernatant was mixed (thoroughly) for three minutes with a whirlpool blender. Afterward, by a magnet (external), the adsorbent was collected to the side of the vial. This phase was repeated one more time, and then the prepared mixture was exposed to a flow (gentle) of pure gas of $\mathrm{N}_{2}$ in order to evaporate the solvent at room temperature. The remainder was re-dissolved in methanol/acetonitrile (50:50 v/v, $50 \mu \mathrm{L}$ ) and then by the vortex-mixer (one minute) the solution was shaken (vigorously). Ultimately, with a syringe, $1 \mu \mathrm{L}$ of the prepared solution was injected into the device of GC/MS (Moazzen et al. 2013). Blank samples containing I.S and quality control (QC) samples were ready and tested in the start, the middle, and at the end of each sample queue. Lastly, all cereals samples were examined in triplicate, and their mean values were used for quantification.

\subsection{Analytical and instrumental conditions}

The analysis was done on a GC-MS (Agilent 6890 GC device and MS detector 5973 quadrupoles Agilent Technologies, Palo Alto, CA, USA). The column of GC was capillary of DB-5 ms (30 meters, 0.25 millimeters i.d., 0.25 micrometers film thickness) and the splitless mode of GC was for the inlet. The temperatures of GC-MS were: injector $290^{\circ} \mathrm{C}$; the primary oven temperature was 70 centigrade degree, retained for 1 minute and raised to 295 centigrade degree at a rate of ten centigrade degree per minutes then retained for seven minutes. The temperature of transfer line was retained at 300 centigrade degree and the flow (constant) of carrier gas (helium) was one milliliter per minute. The temperature of quadrupole was retained at 150 centigrade degree and temperatures of source were kept at 230 centigrade degree. At $70 \mathrm{eV}$, the MS energy of the electronic beam was adjusted. The identification phase was performed by comparing the attained mass spectra and times of retention to reference spectra. By injection of the calibration standards in the same GC/MS conditions, the retention times were attained. The spike standard of calibration approach to overcome the problems caused by the matrix was applied. In this technique, by the addition of standards solution to samples, calibration standards are prepared which are subjected to the same procedure of sample preparation that is intended to be used for unknown samples. By using SIM mode, the analytes of PAHs were quantified and each sample (in duplicate) was injected.

\subsection{Dietary exposure estimates}

The carcinogenic risk of a PAH mixture is mainly represented by BaP equivalent concentration (BaPeq) and the toxicity equivalency factor (TEF) in Table 1, which is considered as a superior set for evaluating the carcinogenic potency of PAH mixtures. Therefore, this set of TEFs was adopted to calculate BaPeq in the present study (Xia et al. 2010). The BaPeq of food (BEC) was calculated according to Eq. (1). 
Table 1

PAHs and their toxic equivalent factors (TEFs)

\begin{tabular}{|llll|}
\hline PAHs & TEF & PAHs & TEF \\
\hline Benzo(a)pyrene (BaP) & 1 & Anthracene (ANT) & 0.01 \\
\hline Dibenz(a,h)anthracene (DahA) & 1 & Naphthalene (NAP) & 0.001 \\
\hline Benzo(k)fluoranthene (BkF) & 0.1 & Acenaphthylene (ACY) & 0.001 \\
\hline Indeno(I,2,3-cd)pyrene (IcdP) & 0.1 & Acenaphthene (ACE) & 0.001 \\
\hline Benz(a)anthracene (BaA) & 0.1 & Phenanthrene (PHE) & 0.001 \\
\hline Benzo(b)fluoranthene (BbF) & 0.1 & Fluorine (FLO) & 0.001 \\
\hline Chrysene (CHR) & 0.01 & Pyrene (PYR) & 0.001 \\
\hline Benzo(g,h,i)perylene (BghiP) & 0.01 & Fluoranthene (FLA) & 0.001 \\
\hline
\end{tabular}

Note. PAHs: Polycyclic aromatic hydrocarbons.

$$
B E C=\sum_{i=1}^{n} C_{i} \times T E F
$$

1

where $\mathrm{Ci}$ and TEFi denote the concentration of the PAHs in bread other cereal products and the TEF of the PAH, respectively. For an individual PAH, the value is assumed to be half of the respective limit of detection (LOD) when the measured concentration is below the LOD. The carcinogenic potencies of these 16 $\mathrm{PAHs}$ were estimated as the sum of each individual BaPeq.

Daily dietary PAH exposure levels (ED) for each group were calculated by Eq. (2).

$$
E_{D}=\sum_{i=1}^{n} B E C_{i} \times I R_{i}
$$

2

where BECi and IRj represent the BaPeq concentration of PAHs in food $i(\mathrm{ng} / \mathrm{g})$ and the ingestion amount of food $i$ per day (g/d), respectively. Moreover, the ingestion amount of foods by each group was obtained from questionnaires which were distributed among the citizens of Tehran.

\subsection{Cancer risk evaluations}

The incremental lifetime cancer risk (ILCR) of individual groups in Tehran due to PAH dietary exposure was calculated based on Eq. (3).

$$
I L C R=E D \times E F \times E_{D} \times C S F \times C F / B W \times A T
$$

3

where $I L C R$ is the incremental lifetime cancer risk of dietary exposure (dimensionless) and CSF indicates the oral cancer slope factor of BaP (7.3 per mg/kg/d) (USEPA. Risk assessment guidance for Superfund: volume III part A \&risk assessment. Washington). In addition, $E_{D}, E D$, and BW denote the daily dietary PAH exposure level (ng/d), exposure duration (year), and body weight $(\mathrm{kg})$, respectively. Finally, $A T$, $E F$, and $C F$ represent the average lifespan for carcinogens (25,550 days), the exposure frequency (365 days/year), and the conversion factor $\left(10^{-6} \mathrm{mg} / \mathrm{ng}\right)$, respectively.

\subsection{Data analysis}

The risk assessment procedure is associated with uncertainty which may occur due to uncertainty in the measurement of factors. Therefore, uncertainty analysis is essential to achieving a more accurate result. In the present study, the uncertainty analysis of Monte Carlo was used to assess uncertainty in the exposure assessment. Further, the results were revealed as mean \pm standard deviation, and the statistical analysis was conducted by SPSS software, version 24.0. In conclusion, $1 / 2$ of the LOD was applied to calculate the mean level in cases that PAH analytes were undetectable. Multivariate techniques were applied to evaluate the correlation between the type and amount of 16 PAHs and cereals samples (Arabameri et al. 2019, Heydarieh et al. 2020). The Principal Component Analysis (PCA) performed by the SPSS software (Version 18.0; Illinois, USA). Heat map analysis was used to analyze the correlation between samples online at https://biit.cs.ut.ee/clustvis/.

\section{Results And Discussion}

\subsection{Performance evaluation of analytical method}

By using a device of GC-MS, the extracted PAHs (from samples) were determined. Toward the recognition objective, the full scan mass spectrum, four ratios of characteristic ions, and the RTT of \pm 0.5 percent tolerance criteria were applied for purpose of the quantification compared to the standard. For each compound, the most intense ions were applied. By using mode of SIM (selected ion monitoring) these compounds were quantified. For each compound, 1 quantitation and 2 qualifier ions were controlled, according to Moazzen et al. (2013), Moreover, the conditions of optimum for the analysis were applied for

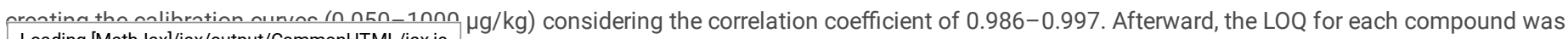
Loading [MathJax]/jax/output/CommonHTML/jax.js 
determined according to the guideline of the international council for harmonization (Moazzen et al. 2013). According to the results, the LOQ and LOD of PAHs compounds were $0.105-0.180$ and $0.035-0.060 \mu \mathrm{g} / \mathrm{kg}$, respectively. In addition, the method accuracy was assessed based on interday precision by the quality control analysis for the prepared samples at four concentrations on three repeated days. Further, the values of interday precision for all PAH compounds were less than 9.8 , and the recorded values were $4.3-12.1$ and $6.1-20.3 \%$ for repeatability and reproducibility with an estimated recovery of $94.4-$ $103.4 \%$, respectively. Furthermore, the feasibility and reliability of this method were confirmed by measuring PAHs in cereals, and no interfering peak was observed in the internal standard area and analytes.

\subsection{The concentrations of PAHs in cereals}

By the EPA, sixteen marker PAHs are listed owing to their common prevalence in the food although they aren 't involved in the legislation of food by most countries. BaP has been extensively recognized as an indicator of the presence of carcinogenic PAHs in a limited number of food categories. For the first time, European Commission (EU) legislated maximum level of the BaP in numerous foodstuffs $(1.0 \mu \mathrm{g} / \mathrm{kg}$ for the processed cereal-based to $10 \mu \mathrm{g} / \mathrm{kg}$ for dried plants). The level of sum sixteen PAHs in cereal products ranged from 98.2 (in Barbari bread) to $248.3 \mu \mathrm{g} / \mathrm{kg}$ (in rice cooked). The level of eight PAHs in cereal products ranged from n.d (1/2 LOD) to $16.6 \mu \mathrm{g} / \mathrm{kg}$. Among 16 PAHs, NAP had the highest level (101.5 $\mu \mathrm{g} / \mathrm{kg}$ in rice cooked) and BbF, BkF, BaP, DahiP and BghiP had the lowest level (n.d) in all tested food (Table 2).

Table 2

The mean of concentration of PAHs in cereal product samples $(\mu \mathrm{g} / \mathrm{kg})$

\begin{tabular}{|c|c|c|c|c|c|c|c|c|c|c|c|c|c|c|c|c|c|}
\hline & & \multicolumn{16}{|c|}{$\mathrm{PAHs}(\mathrm{ppb})$} \\
\hline & & NAP & ACY & ACE & FLO & PHE & ANT & FLA & PYR & $\mathrm{BaA}$ & CHR & $\mathrm{BbFF}$ & BkF & $\mathrm{BaP}$ & DahA & BghiP & IcdP \\
\hline & & \multicolumn{16}{|c|}{ mean $\pm S D$} \\
\hline \multirow[t]{8}{*}{$\begin{array}{l}\text { Cereal } \\
\text { products }\end{array}$} & $\begin{array}{l}\text { Barbari } \\
\text { bread }\end{array}$ & $\begin{array}{l}36.4 \\
\pm \\
1.302\end{array}$ & $\begin{array}{l}7.6 \\
\pm \\
0.32\end{array}$ & $\begin{array}{l}21.2 \\
\pm \\
1.02\end{array}$ & $\begin{array}{l}5.5 \\
\pm \\
0.10\end{array}$ & $\begin{array}{l}9.8 \\
\pm \\
0.20\end{array}$ & $\begin{array}{l}3.6 \pm \\
0.11\end{array}$ & $\begin{array}{l}4.4 \\
\pm \\
0.20\end{array}$ & $\begin{array}{l}7.1 \\
\pm \\
0.20\end{array}$ & $\begin{array}{l}0.1 \\
\pm \\
0.00\end{array}$ & $\begin{array}{l}2.6 \\
\pm \\
0.10\end{array}$ & n.d & n.d & n.d & n.d & n.d & n.d \\
\hline & $\begin{array}{l}\text { Sangak } \\
\text { bread }\end{array}$ & $\begin{array}{l}59.2 \\
\pm 2.32\end{array}$ & $\begin{array}{l}15.0 \\
\pm \\
1.32\end{array}$ & $\begin{array}{l}18.8 \\
\pm \\
1.40\end{array}$ & $\begin{array}{l}8.4 \\
\pm \\
0.20\end{array}$ & $\begin{array}{l}4.3 \\
\pm \\
0.11\end{array}$ & $\begin{array}{l}6.5 \pm \\
0.20\end{array}$ & $\begin{array}{l}4.2 \\
\pm \\
0.11\end{array}$ & $\begin{array}{l}2.2 \\
\pm \\
0.00\end{array}$ & n.d & $\begin{array}{l}3.2 \\
\pm \\
0.10\end{array}$ & n.d & n.d & n.d & n.d & n.d & n.d \\
\hline & Baguette & $\begin{array}{l}53.2 \\
\pm 1.82\end{array}$ & $\begin{array}{l}4.9 \\
\pm \\
0.12\end{array}$ & $\begin{array}{l}24.1 \\
\pm \\
1.42\end{array}$ & $\begin{array}{l}6.2 \\
\pm \\
0.10\end{array}$ & $\begin{array}{l}12.9 \\
\pm \\
0.20\end{array}$ & $\begin{array}{l}8.8 \pm \\
0.11\end{array}$ & $\begin{array}{l}7.4 \\
\pm \\
0.22\end{array}$ & $\begin{array}{l}5.8 \\
\pm \\
0.30\end{array}$ & n.d & $\begin{array}{l}11.6 \\
\pm \\
0.40\end{array}$ & n.d & n.d & n.d & n.d & n.d & n.d \\
\hline & $\begin{array}{l}\text { Taftoun } \\
\text { bread }\end{array}$ & $\begin{array}{l}69.6 \\
\pm 3.32\end{array}$ & $\begin{array}{l}17.8 \\
\pm \\
0.78\end{array}$ & $\begin{array}{l}20.8 \\
\pm \\
1.72\end{array}$ & $\begin{array}{l}9.7 \\
\pm \\
0.50\end{array}$ & $\begin{array}{l}5.0 \\
\pm \\
0.11\end{array}$ & $\begin{array}{l}12.7 \\
\pm \\
0.50\end{array}$ & $\begin{array}{l}10.4 \\
\pm \\
0.11\end{array}$ & $\begin{array}{l}6.6 \\
\pm \\
0.20\end{array}$ & $\begin{array}{l}1.5 \\
\pm \\
0.00\end{array}$ & $\begin{array}{l}12.2 \\
\pm \\
0.33\end{array}$ & n.d & n.d & n.d & n.d & n.d & n.d \\
\hline & $\begin{array}{l}\text { Lavash } \\
\text { Bread }\end{array}$ & $\begin{array}{l}59.9 \\
\pm 2.00\end{array}$ & $\begin{array}{l}23.5 \\
\pm \\
0.54\end{array}$ & $\begin{array}{l}42.8 \\
\pm \\
1.00\end{array}$ & $\begin{array}{l}16.4 \\
\pm \\
1.10\end{array}$ & $\begin{array}{l}2.1 \\
\pm \\
0.20\end{array}$ & $\begin{array}{l}17.8 \\
\pm \\
0.10\end{array}$ & $\begin{array}{l}8.7 \\
\pm \\
0.20\end{array}$ & $\begin{array}{l}5.1 \\
\pm \\
0.11\end{array}$ & n.d & n.d & n.d & n.d & n.d & n.d & n.d & n.d \\
\hline & Macaroni & $\begin{array}{l}80.6 \\
\pm 2.02\end{array}$ & $\begin{array}{l}21.8 \\
\pm \\
1.12\end{array}$ & $\begin{array}{l}24.5 \\
\pm \\
1.02\end{array}$ & $\begin{array}{l}8.6 \\
\pm \\
0.50\end{array}$ & $\begin{array}{l}6.2 \\
\pm \\
0.00\end{array}$ & $\begin{array}{l}16.6 \\
\pm \\
1.101\end{array}$ & $\begin{array}{l}7.6 \\
\pm \\
0.11\end{array}$ & $\begin{array}{l}6.8 \\
\pm \\
0.10\end{array}$ & $\begin{array}{l}0.3 \\
\pm \\
0.01\end{array}$ & $\begin{array}{l}3.2 \\
\pm \\
0.20\end{array}$ & n.d & n.d & n.d & n.d & n.d & n.d \\
\hline & Lasagna & $\begin{array}{l}69.3 \\
\pm 1.11\end{array}$ & $\begin{array}{l}14.8 \\
\pm \\
1.11\end{array}$ & $\begin{array}{l}20.5 \\
\pm \\
1.30\end{array}$ & $\begin{array}{l}9.6 \\
\pm \\
1.66\end{array}$ & $\begin{array}{l}2.2 \\
\pm \\
0.00\end{array}$ & $\begin{array}{l}8.6 \pm \\
0.31\end{array}$ & $\begin{array}{l}3.2 \\
\pm \\
0.31\end{array}$ & $\begin{array}{l}1.8 \\
\pm \\
0.00\end{array}$ & n.d & n.d & n.d & n.d & n.d & n.d & n.d & n.d \\
\hline & $\begin{array}{l}\text { Cooked } \\
\text { rice }\end{array}$ & $\begin{array}{l}101.5 \\
\pm 4.12\end{array}$ & $\begin{array}{l}7.1 \\
\pm \\
0.14\end{array}$ & $\begin{array}{l}33.8 \\
\pm \\
1.00\end{array}$ & $\begin{array}{l}45.2 \\
\pm \\
1.77\end{array}$ & $\begin{array}{l}7.2 \\
\pm \\
1.20\end{array}$ & $\begin{array}{l}11.1 \\
\pm \\
0.41\end{array}$ & $\begin{array}{l}13.6 \\
\pm \\
0.20\end{array}$ & $\begin{array}{l}12.2 \\
\pm \\
0.20\end{array}$ & n.d & $\begin{array}{l}16.6 \\
\pm \\
0.31\end{array}$ & n.d & n.d & n.d & n.d & n.d & n.d \\
\hline
\end{tabular}

In the present study, B[b]F, BaP, B[k]F, DahA, BghiP, and IcdP were detected in none of the cereal products, which is in line with the results of a study conducted in India.

Ciecierska and Obiedziński found that the total content of 19 PAHs in wheat, flour and wheat bran were 1.07 to $3.65 \mu \mathrm{g} / \mathrm{kg}$ and at different levels of bread were 1.59 to $13.6 \mu \mathrm{g} / \mathrm{kg}$ that was lower than our study. Based on the contamination of flour, dough and the effect of baking temperature on the amount of bread PAHs, it was confirmed that the formation of PAHs increases during baking(Ciecierska \&Obiedziński 2013).

Kamalabadi et al found that the total mean level 16 PAHs and 4 indicator PAHs (BaP, BaA, BbF, and chry) in bread samples were 84.17 and $0.93 \mu \mathrm{g} / \mathrm{kg}$, respectively, which was higher than our study(Kamalabadi et al. 2019).

Abdul-Gafaru showed that the level of PAHs bread samples ranged from 0.54 to $5.1212 \mu \mathrm{g} / \mathrm{kg}$, while the level of BaP ranged from 0.0021 to $3.99 \mu \mathrm{g} / \mathrm{kg}$ wet weight (w / w), which was BaP was higher than our result (Abdul-Gafaru 2018). 
Jahed et al. showed that the average level of PAHs in bread samples is from 0.2 to $8.7 \mu \mathrm{g} / \mathrm{kg}$, which was lower than our results. The highest level of PAHs was in Barbari bread with a value of $8.7 \mu \mathrm{g} / \mathrm{kg}$ and the lowest level was $0.2 \mu \mathrm{g} / \mathrm{kg}$ in industrial bread (Jahed Khaniki et al. 2021).

Roszko et al. showed that the mean concentration of $\mathrm{BaP}$ in the wheat samples was $0.03 \pm 0.03 \mu \mathrm{g} / \mathrm{kg}$ and mean concentration of $4 \mathrm{PAH}(\mathrm{BaA}+\mathrm{BaP}+\mathrm{chry}+$ $\mathrm{BbF}$ ) was $0.43 \pm 0.16 \mu \mathrm{g} / \mathrm{kg}$, which was BaP higher than our result(Roszko et al. 2020).

Rascon et al. showed that in most samples tested, Nap and Ant were in concentrations of 13 to $5500 \mathrm{ng} / \mathrm{kg}$. In the three samples of cereals (granola, granola chocolate and cereal with milk) and flatbread, the PAH4 (BaP, BaA, BbF and Chry) levels exceeded the limit set by the European Commission ( $1 \mu \mathrm{g} / \mathrm{kg})$, which was somewhat similar to the our study (Rascon et al. 2018).

Bertinetti et al. measurement PAHs in rice and reported the total PAHs were ranged from $6.9 \pm 0.4$ (drying with Electric heating) to $216.6 \pm 11.4 \mu \mathrm{g} / \mathrm{kg}$ (driyng with Eucalyptus sp. wood) which was lower than our study (Bertinetti et al. 2018).

Liu et al. assessment the PAHs in unpolished rice and reported that the total PAHs were ranged from 46 to $77 \mu \mathrm{g} / \mathrm{kg}$, and they also showed the mean on total PAHs in unpolished and polished rice were $58 \pm 9.5$ and $19 \pm 2.6 \mu \mathrm{g} / \mathrm{kg}$, respectively, which was lower than our result (Liu \&Korenaga 2001).

Ihedioha et al. measurement the PAHs in macaroni and reported that the total PAHs were ranged from $30.0 \pm 3.0$ to $60.0 \pm 10.0 \mu \mathrm{g} / \mathrm{Kg}$, which was lower than our study (Ihedioha et al. 2019).

Food can be contaminated with PAHs through industrial processes during the process of food production, home cooking and environmental pollution. PAHs compounds have been identified in many food groups, especially breads, cereals and cereal products. Bread and breakfast cereals can be contaminated through bakery raw materials (primarily flour), water, and the baking process(Kacmaz 2019).

\subsection{Principal component analysis}

PCA was applied to understanding the relationships among the light and heavy PAHs with cereal product samples. The PCA score plot in Fig. 3 shows that the distribution of variability can be explained for $87 \%$ of the total variance by three principal components. PC 1 accounted for $46 \%$ of the variance and characterized by a features vector of PAHs. This compound had a highly positive correlation with Fl, total PAH, NaP and Pyr, but they had a significant and negative correlation with Phe and AcP. Meanwhile, the second factor (PC2) described $26.7 \%$ of the total variance and this component had highly positive correlation with AcPY but they had a significant and negative correlation with Phe and Chr. The PC3 described 13.3\% of the total variance and this component had highly positive correlation with $\mathrm{BaA}$, but they had a significant and negative correlation with AcP, Fl and total PAHs. It can be observed that cereal product samples are effectively divided according to their distribution PAHs against the different types. In all samples, NaP, FI and total PAHs were the closest, indicating that the variables had similar distribution. Further, heat map analysis proposed to cluster with cereal product samples based on their contaminated with individual PAHs. ClustVis was applied to visualizing clustering of similarity and variability data and the results of the same have been shown in Figs. 1 and 2 .

A simple heat map provides a very general impression of the largest and smallest variables in the generating matrix besides clustering columns and rows of similar variable. The cereal products heat map clustered 8 gropes samples into four major clusters and two sub clusters is shown in Fig. 2 . First cluster includes only Lavash bread, Second cluster includes only rice cooked (Chelo), and third cluster contains two sub-groups with all samples except Lavash bread and rice cooked samples. In assessing the correlation between the type and amount of 16 PAHs in cereal product samples, resulting dendrogram showed two groups composed. One cluster includes total PAH, NAP and FI. In consideration of the different PAHs in samples, these compounds are classified separately from each other and generated a linked contribution to simple differentiation in cereal product samples. In consideration of the different PAHs in samples, these compounds can be classified separately into various subgroups based on their levels and generated a linked contribution to simple differentiation in cereal product samples. The total heat maps dendrogram showed that the PAHs profile of total PAH, NAP and FLO were close to each other. Also, BaA, AcPY, $\mathrm{NaP}$, Phe, Chr, Pyr, Phe and AcP are isolated from the others by their groups. Moreover, heat maps indicated that the different types of cereal product is considered as independent variables to the clustering of PAHs in samples.

\subsection{Daily exposure estimation of PAHs}

The daily exposure estimation of PAHs was conducted as presented in Sect. 2.5. The cereal products consumption per person per day was computed through a food frequency questionnaire, followed by calculating dietary intake with the PAHs concentration in cereal products. According to data in Table 3 , the higher ED value of PAHs in four groups of cereal product by Tehran citizens was in rice cooked ( $1.02 \mu \mathrm{g} / \mathrm{kg} / \mathrm{day})$ and then Sangak bread ( $0.35 \mu \mathrm{g} / \mathrm{kg} / \mathrm{day})$. Likewise, the higher ED values of PAHs in four groups of cereals by Tehran citizens was in Lasagna cooked $(0.03 \mu \mathrm{g} / \mathrm{kg} / \mathrm{day})$. 
Table 3

Uncertainty analysis for the CDi and ILCR of

investigated PAH content in cereal product

\begin{tabular}{|lllll|}
\hline \multicolumn{5}{c}{ samples } \\
\hline Percentiles & $\mathbf{5 \%}$ & $\mathbf{5 0 \%}$ & $\mathbf{7 5 \%}$ & $\mathbf{9 5 \%}$ \\
\hline Barbari bread & 0.12 & 0.18 & 0.22 & 0.27 \\
\hline Sangak bread & 0.17 & 0.24 & 0.28 & 0.35 \\
\hline baguette & 0.12 & 0.18 & 0.21 & 0.26 \\
\hline Taftoun bread & 0.09 & 0.13 & 0.16 & 0.19 \\
\hline Lavash bread & 0.14 & 0.22 & 0.25 & 0.32 \\
\hline Macaroni & 0.06 & 0.09 & 0.10 & 0.13 \\
\hline Lasagna & 0.01 & 0.02 & 0.02 & 0.03 \\
\hline Cooked rice & 0.46 & 0.67 & 0.79 & 1.02 \\
\hline
\end{tabular}

In a study in Spain, the level of daily dietary in bread, cookies, cakes, rice and related products ranged from 0.14 to $8.6 \mu \mathrm{g} / \mathrm{kg} / \mathrm{day}$, which is in line with the findings of the present study (Ibanez et al. 2005). Studies in Kuwait have shown daily intakes of BaP in bread range from 0.85 to $4.96 \mu \mathrm{g} / \mathrm{kg} / \mathrm{day}$ (Al-Rashdan et al. 2010). According to data presented by some countries, the Joint Expert Committee on Food Additives (JECFA) (2005) reported a mean BaP intake of 4 $\mathrm{ng} / \mathrm{kg}$ bw/day, conforming to a daily intake of $280 \mathrm{ng}$ per person. Further, the European Food Safety Authority (2008) presented a mean BaP intake of $235 \mathrm{ng}$ per person for average dietary consumers and $389 \mathrm{ng} /$ day for high dietary consumers (Abramsson-Zetterberg et al. 2014).

\subsection{Health risk assessment}

Assessment of exposure is one of the most significant constituents of risk measurement which is used to evaluate the probability and extent of individuals' exposure to chemical substance (KHALILI et al. 2019). Based on the US EPA reports, $10^{-6}$ chance of additional human cancer over a 70-year lifetime (ILCR = $\left.10^{-6}\right)$ is the risk considered acceptable level or the insignificant level, which is favorably comparable with the risk level of some routine activity, and the work like (Asante-Duah 2002).

The increased risk of cancer in a lifetime is considered serious in $10^{4}$ or greater number of people (ILCR $=10^{-4}$ ). Therefore, paying attention to this health problem is of high priority. Tables 4 and Fig. 4 indicate the distribution of ILCR after 20000 iterations and with a probability of 50, 75 and $95 \%$.

Table 4

Uncertainty analysis for the ILCR of investigated PAH content in cereal product samples

\begin{tabular}{|lllll|}
\hline Percentiles & $\mathbf{5} \%$ & $\mathbf{5 0} \%$ & $\mathbf{7 5} \%$ & $\mathbf{9 5 \%}$ \\
\hline Barbari bread & $8.47 \mathrm{E}-7$ & $1.35 \mathrm{E}-6$ & $1.59 \mathrm{E}-6$ & $2.05 \mathrm{E}-6$ \\
\hline Sangak bread & $1.12 \mathrm{E}-6$ & $1.73 \mathrm{E}-6$ & $2.09 \mathrm{E}-6$ & $2.68 \mathrm{E}-6$ \\
\hline baguette & $8.53 \mathrm{E}-7$ & $1.28 \mathrm{E}-6$ & $1.53 \mathrm{E}-6$ & $1.95 \mathrm{E}-6$ \\
\hline Taftoun bread & $6.18 \mathrm{E}-7$ & $9.41 \mathrm{E}-7$ & $1.12 \mathrm{E}-6$ & $1.42 \mathrm{E}-6$ \\
\hline Lavash bread & $9.98 \mathrm{E}-7$ & $1.54 \mathrm{E}-6$ & $1.83 \mathrm{E}-6$ & $2.28 \mathrm{E}-6$ \\
\hline Macaroni & $4.09 \mathrm{E}-7$ & $6.25 \mathrm{E}-7$ & $7.50 \mathrm{E}-7$ & $9.65 \mathrm{E}-7$ \\
\hline Lasagna & $9.72 \mathrm{E}-8$ & $1.51 \mathrm{E}-7$ & $1.80 \mathrm{E}-7$ & $2.35 \mathrm{E}-7$ \\
\hline Cooked rice & $3.11 \mathrm{E}-6$ & $4.94 \mathrm{E}-6$ & $5.87 \mathrm{E}-6$ & $7.80 \mathrm{E}-6$ \\
\hline
\end{tabular}

The mean of contributions to overall ILCR in cereals was estimated to be $5.20 \mathrm{E}-05$ and $7.73 \mathrm{E}-05$, respectively, which was higher than the acceptable risk level $\left(10^{-6}\right)$. Those between $10^{-6}$ and $10^{-4}$ indicate a low health risk. The results of a study in Spain showed that the PAHs total daily intake is related to a $5 E 10-6$ increase in cancer risk in an adult male weighing $70 \mathrm{~kg}$ (Falco et al. 2003) compared to the findings of the present study. The MCS results for the cereal products samples revealed that the rank order of the ILCR index was rice cooked $>$ Sangak bread $>$ Lavash bread $>$ Barbari bread $>$ baguette $>$ Taftoun bread $>$ macaroni cooked $>$ masagna cooked. According to the outcomes of the current research, the highest ILCR in the four groups of cereals belonged to rice cooked (7.80E-06), while the lowest was found in Lasagna (2.35E-07). (Table 4 and Fig. 3).

\section{Conclusion}


The cereal products samples were analyzed for sixteen marker PAHs, using magnetic solid-phase extraction (MSPE) clean up and detected GC/MS. Among 16 PAHs, NAP had the highest level (101.5 $\mathrm{g} / \mathrm{kg}$ in rice cooked) and BbF, BkF, BaP, DahiP and BghiP had the lowest level (n.d) in all tested foods. The findings obtained in this study demonstrate the differences and similarities among the 16 PAHs in cereal products samples by PCA as by Heat map analysis.

Eventually, the Monte Carlo Simulation results for ILCR indexes in cereals were estimated to be $5.20 \mathrm{E}-05$ and 7.73E-05, respectively, which was higher than the acceptable risk level $\left(10^{-6}\right)$. On the other hand, monitoring should continue, because the quality of cereal products may vary from year to year. Therefore, cereal products should be regularly evaluated and monitored by regulatory agencies to reduce contaminants in these high-consumption products.

\section{Declarations}

Acknowledgments: This study was supported by the Tehran University of Medical Science, Tehran, Iran.

Disclosure statement: The authors declare that they have no conflicts interest

Ethical Approval: "This study does not involve any human or animal testing" or "This study was approved by the Tehran University of Medical Science

Consent to participate: All authors participated in this work.

Consent to publish; All authors agree to publish.

Data availability: The datasets used and/or analyzed during the current study are available from the corresponding author on reasonable request.

Author's contributions: Nabi Shariatifar. Conceptualization, Supervision, Design of study, Writing- Reviewing and Editing. Mohammad Hadi Dehghani: Design of study, Writing- Reviewing and Editing. Ramin Nabizadeh: Data curation, Writing- Reviewing and Editing. Majd Arabameri: Visualization, Investigation, Saftware, Methodology. Software, Validation, Fariba Khalili: Methodology. Software, Validation, Maryam Moazzen: Data curation, Writing- Original draft preparation, Kamyar Yaghmaeian: Design of study, Writing- Reviewing and Editing. Mehdi Yaseri :Saftware, Methodology

\section{References}

1. Abdul-Gafaru O 2018: Health risk assessment of PAH in bread

2. Abramsson-Zetterberg L, Darnerud PO, Wretling S (2014): Low intake of polycyclic aromatic hydrocarbons in Sweden: Results based on market basket data and a barbecue study. Food and Chemical Toxicology 74, 107-111

3. Ahmadkhaniha R, Shafiee A, Rastkari N, Kobarfard F (2009): Accurate quantification of endogenous androgenic steroids in cattle's meat by gas chromatography mass spectrometry using a surrogate analyte approach. Analytica chimica acta 631, 80-86

4. Al-Rashdan A, Helaleh MI, Nisar A, Ibtisam A, Al-Ballam Z (2010): Determination of the levels of polycyclic aromatic hydrocarbons in toasted bread using gas chromatography mass spectrometry. International journal of analytical chemistry 2010

5. Arabameri M, Nazari RR, Abdolshahi A, Abdollahzadeh M, Mirzamohammadi S, Shariatifar N, Barba FJ, Mousavi Khaneghah A (2019): Oxidative stability of virgin olive oil: evaluation and prediction with an adaptive neuro-fuzzy inference system (ANFIS). Journal of the Science of Food and Agriculture 99 , 5358-5367

6. Asante-Duah DK (2002): Public health risk assessment for human exposure to chemicals, 6 . Springer

7. Bertinetti IA, Ferreira CD, Monks JLF, Sanches-Filho PJ, Elias MC (2018): Accumulation of polycyclic aromatic hydrocarbons (PAHs) in rice subjected to drying with different fuels plus temperature, industrial processes and cooking. Journal of Food Composition and Analysis 66, 109-115

8. Ciecierska M, Obiedziński M (2013): Polycyclic aromatic hydrocarbons in the bakery chain. Food chemistry 141, 1-9

9. Falco G, Domingo JL, Llobet JM, Teixido A, Casas C, Müller L (2003): Polycyclic aromatic hydrocarbons in foods: human exposure through the diet in Catalonia, Spain. Journal of Food Protection 66, 2325-2331

10. Heydarieh A, Arabameri M, Ebrahimi A, Ashabi A, Monjazeb Marvdashti L, Shokrollahi Yancheshmeh B, Abdolshahi A (2020): Determination of Magnesium, Calcium and Sulphate Ion Impurities in Commercial Edible Salt. Journal of Chemical Health Risks 10, 93-102

11. Ibanez R, Agudo A, Berenguer A, Jakszyn P, Tormo MJ, Sanchez MJ, Quiros JR, Pera G, Navarro C, Martinez C (2005): Dietary intake of polycyclic aromatic hydrocarbons in a Spanish population. Journal of food protection 68, 2190-2195

12. Ihedioha JN, Okali EE, Ekere NR, Ezeofor CC (2019): Risk Assessment of Polycyclic Aromatic Hydrocarbons in Pasta Products Consumed in Nigeria. Iranian Journal of Toxicology 13, 19-26

13. Jahed Khaniki G, Ahmadi M, Ahmadabadi M, Shariatifar N, Ahmadkhaniha R, Rastkari N, Sadighara P (2021): Assessment of polycyclic aromatic hydrocarbons (PAHs) in traditional breads consumed by people in Tehran city of Iran and the calculation of their daily intake. International Journal of Environmental Analytical Chemistry, 1-9

14. Kacmaz S (2019): Polycyclic Aromatic Hydrocarbons (PAHs) in Flour, Bread, and Breakfast Cereals, Flour and Breads and their Fortification in Health and Disease Prevention. Elsevier, pp. 13-20

15. Kamalabadi M, Kamankesh M, Mohammadi A, Hadian Z, Ferdowsi R (2019): Contamination and Daily Intake of Polycyclic Aromatic Hydrocarbons in Iranian Bread Samples. Polycyclic Aromatic Compounds

16. KHALILI F, MAHVI AH, NASSERI S, YUNESIAN M, YASERI M, DJAHED B (2019): Health Risk Assessment of Dermal Exposure to Heavy Metals Content of Chemical Hair Dyes. Iranian Journal of Public Health 48, 902-911

Loading [MathJax]/jax/output/CommonHTML/jax.js 
17. Kiani A, Ahmadloo M, Shariatifar N, Moazzen M, Baghani AN, Khaniki GJ, Taghinezhad A, Kouhpayeh A, Khaneghah AM, Ghajarbeygi P (2018): Method development for determination of migrated phthalate acid esters from polyethylene terephthalate (PET) packaging into traditional Iranian drinking beverage (Doogh) samples: a novel approach of MSPE-GC/MS technique. Environmental Science and Pollution Research 25, 12728-12738

18. Kouhpayeh A, Moazzen M, Jahed Khaniki GR, Dobaradaran S, Shariatifar N, Ahmadloo M, Azari A, Nazmara S, Kiani A, Salari M (2017): Extraction and determination of phthalate esters (PAEs) in Doogh. Journal of Mazandaran University of medical sciences 26, 257-267

19. Lee J, Jeong J-H, Park S, Lee K-G (2018): Monitoring and risk assessment of polycyclic aromatic hydrocarbons (PAHs) in processed foods and their raw materials. Food Control 92, 286-292

20. Lee Y-N, Lee S, Kim J-S, Patra JK, Shin H-S (2019): Chemical analysis techniques and investigation of polycyclic aromatic hydrocarbons in fruit, vegetables and meats and their products. Food chemistry $277,156-161$

21. Liu X, Korenaga T (2001): Dynamics analysis for the distribution of polycyclic aromatic hydrocarbons in rice. Journal of health science 47 , $446-451$

22. Ma T-T, Shen X-F, Yang C, Qian H-L, Pang Y-H, Yan X-P (2019): Covalent immobilization of covalent organic framework on stainless steel wire for solidphase microextraction GC-MS/MS determination of sixteen polycyclic aromatic hydrocarbons in grilled meat samples. Talanta 201, 413-418

23. Moazzen M, Ahmadkhaniha R, Gorji MEh, Yunesian M, Rastkari N (2013): Magnetic solid-phase extraction based on magnetic multi-walled carbon nanotubes for the determination of polycyclic aromatic hydrocarbons in grilled meat samples. Talanta 115, 957-965

24. Moazzen M, Khaneghah AM, Shariatifar N, Ahmadloo M, Eş I, Baghani AN, Yousefinejad S, Alimohammadi M, Azari A, Dobaradaran S (2019): Multi-walled carbon nanotubes modified with iron oxide and silver nanoparticles (MWCNT-Fe304/Ag) as a novel adsorbent for determining PAEs in carbonated soft drinks using magnetic SPE-GC/MS method. Arabian Journal of Chemistry 12, 476-488

25. Mocek K, Ciemniak A (2016): Influence of physical factors on polycyclic aromatic hydrocarbons (PAHs) content in vegetable oils. Journal of Environmental Science and Health, Part B 51, 96-102

26. Palm N-D (2010): Characterization of polycyclic aromatic hydrocarbons (PAH's) present in sampled cooked food.

27. Purcaro G, Moret S, Conte LS (2013): Overview on polycyclic aromatic hydrocarbons: occurrence, legislation and innovative determination in foods. Talanta 105, 292-305

28. Qiao M, Wang C, Huang S, Wang D, Wang Z (2006): Composition, sources, and potential toxicological significance of PAHs in the surface sediments of the Meiliang Bay, Taihu Lake, China. Environment International 32, 28-33

29. Rascon AJ, Azzouz A, Ballesteros E (2018): Assessing polycyclic aromatic hydrocarbons in cereal-based foodstuffs by using a continuous solid-phase extraction system and gas chromatography-mass spectrometry. Food Control 92, 92-100

30. Roszko MŁ, Juszczyk K, Szczepańska M, Świder O, Szymczyk K (2020): Background levels of polycyclic aromatic hydrocarbons and legacy organochlorine pesticides in wheat sampled in 2017 and 2018 in Poland. Environmental monitoring and assessment 192, 1-17

31. Sadowska-Rociek A, Surma M, Cieślik E (2014): Comparison of different modifications on QuEChERS sample preparation method for PAHs determination in black, green, red and white tea. Environmental Science and Pollution Research 21, 1326-1338

\section{Figures}

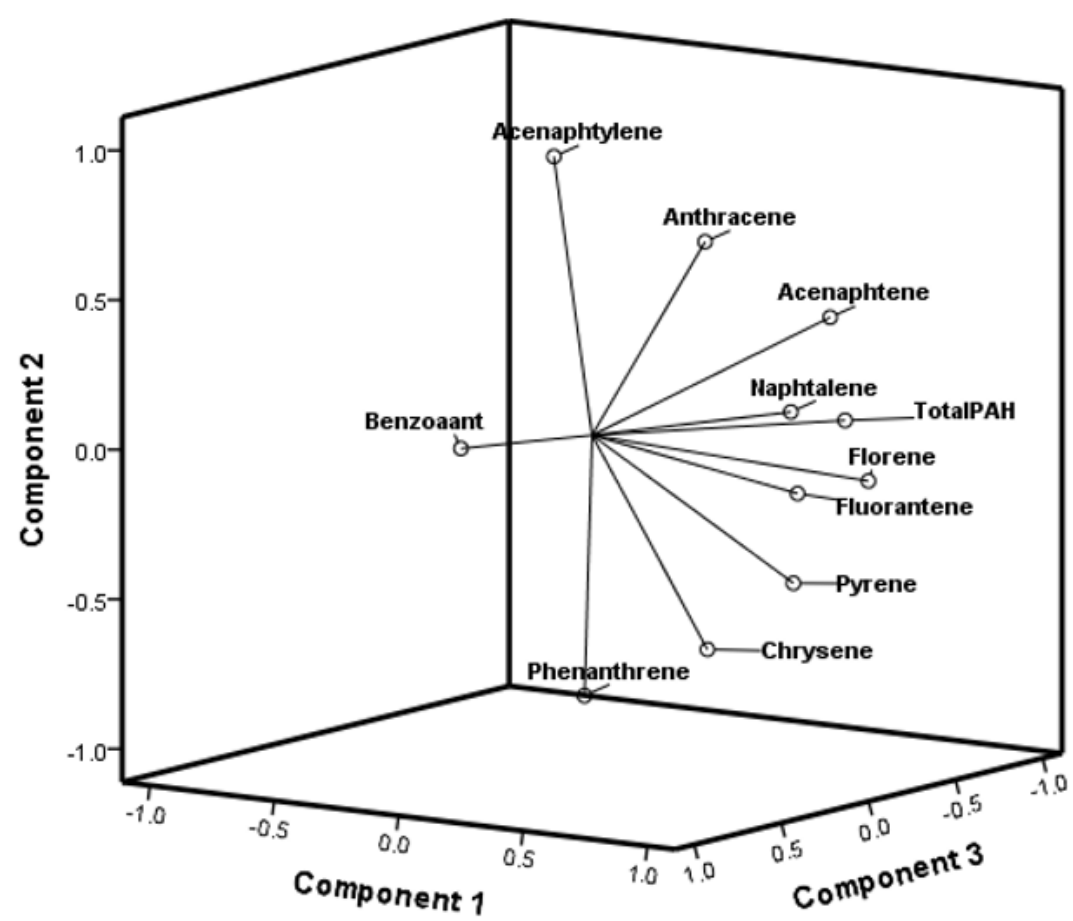

Loading [MathJax]/jax/output/CommonHTML/jax.js 
Principal component analysis loading plot of 16 PAHs in cereal products.

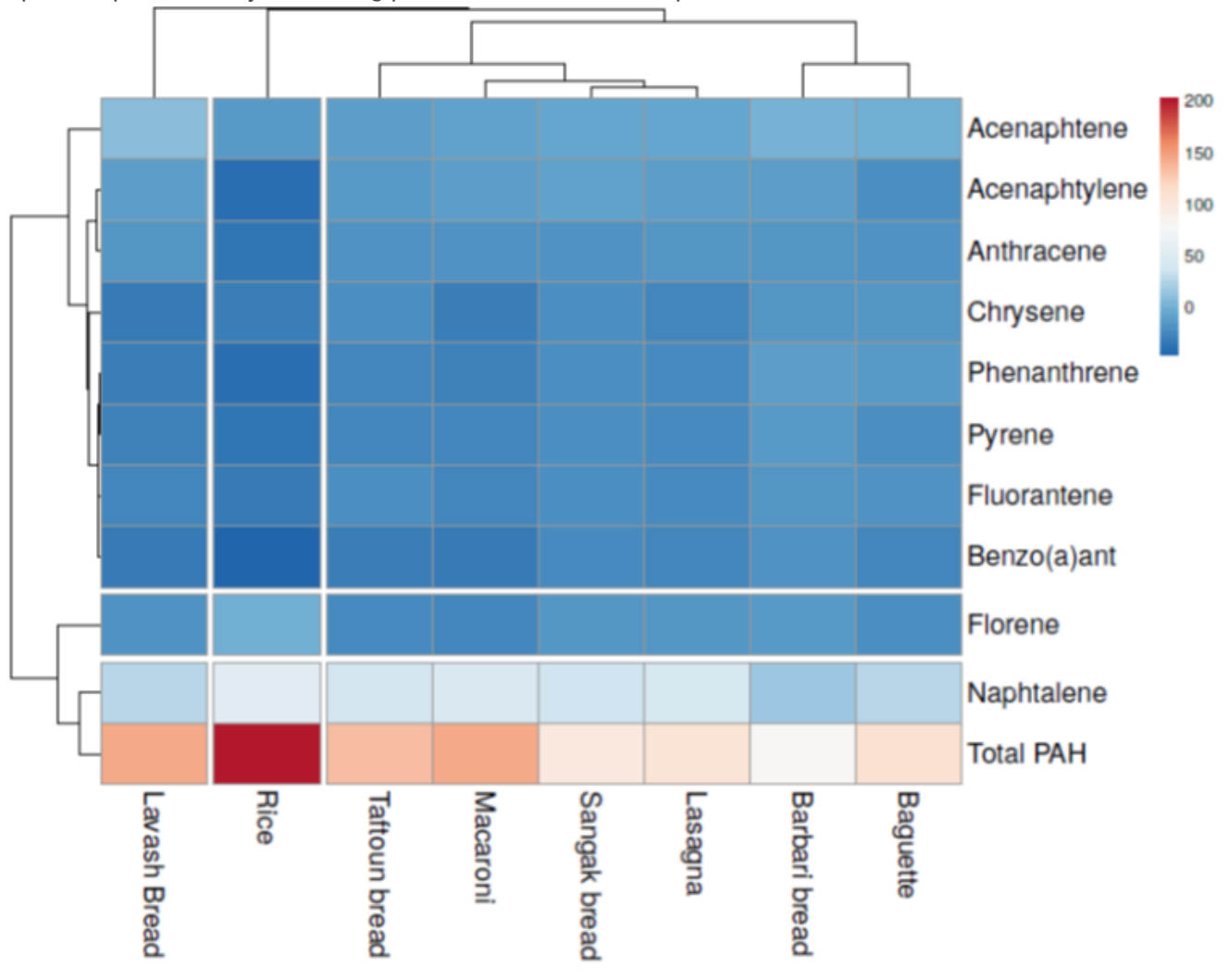

Figure 2

Heat map of 16 PAHs in cereal products 

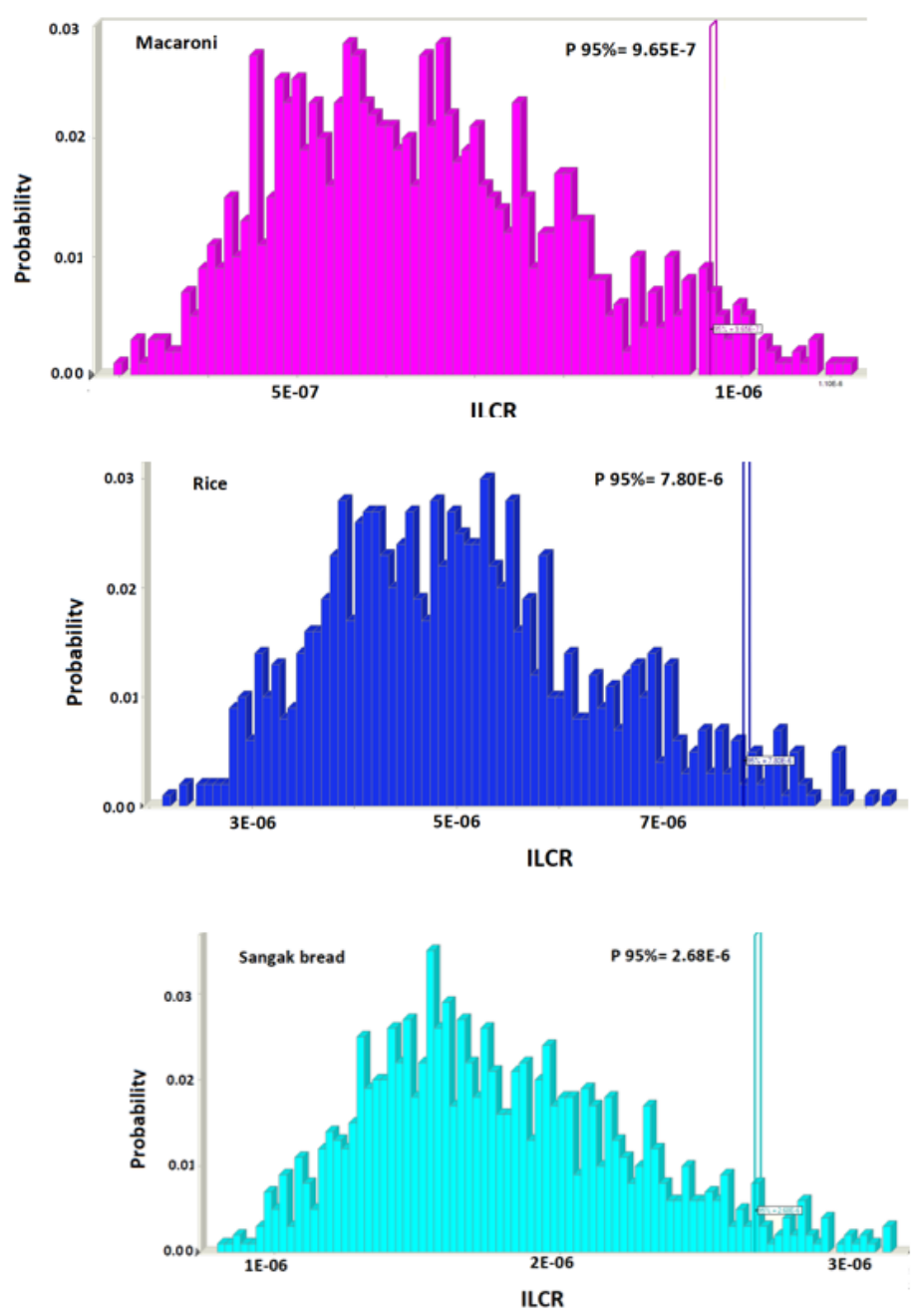

\section{Figure 3}

Simulation results for incremental lifetime cancer risk (ILCR) of PAHs in cereal products.

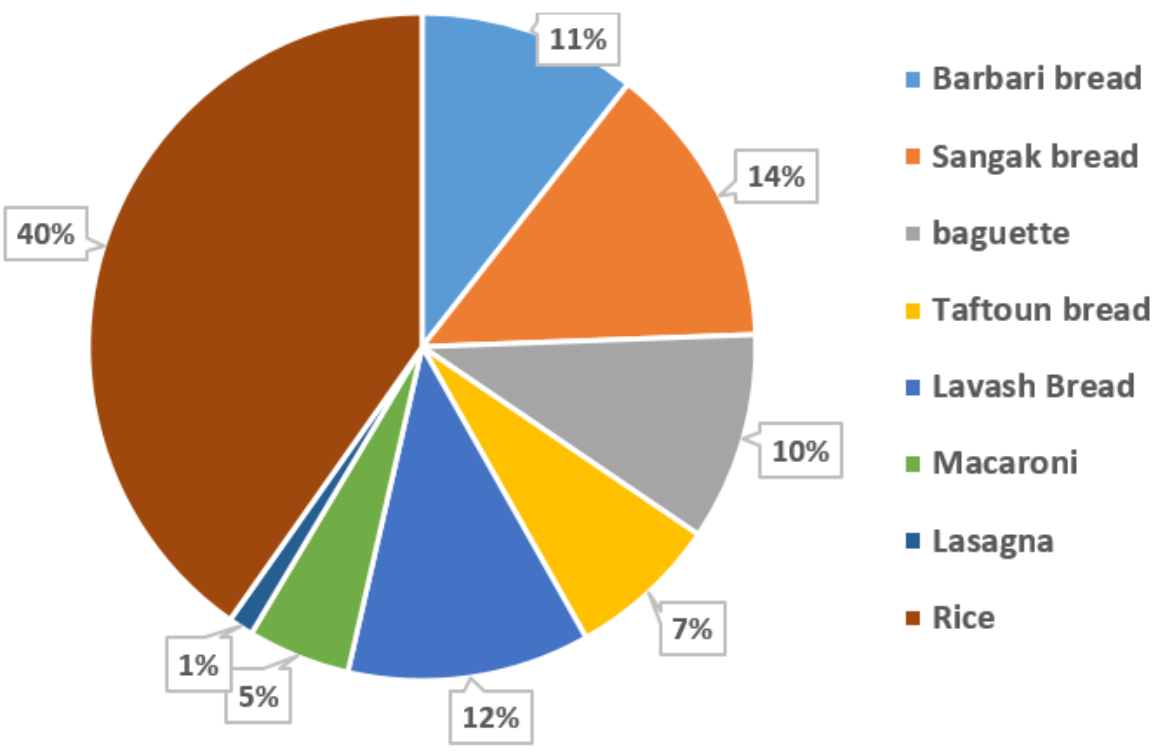

Figure 4

Comnaricnn of the mact and leact nnntrihution to overall ILCR in cereal products. 